\title{
Parvovirus B19 Associated Pure Red Cell Aplasia Associated with R-CHOP Immunochemotherapy for Relapsed B-Cell Non-Hodgkin'S Lymphoma - An Indicator of A Poor Prognosis?
}

\author{
S. Fetscher ${ }^{1 *}$, H. Merz ${ }^{2}$ and J.T. Hartmann ${ }^{3}$
}

${ }^{1}$ Sana Klinikum Süd, Medizinische Klinik III, Lübeck, Germany

${ }^{2}$ Universitätsklinikum Schleswig-Holstein, Campus Lübeck, Institut für Pathologie, Lübeck, Germany

${ }^{3}$ Universitätsklinikum Schleswig-Holstein, Campus Kiel, Klinik für Innere Medizin II, Kiel, Germany

\begin{abstract}
We describe the case of a patient who developed a severe and symptomatic Parvovirus B19 associated anemia during R-CHOP-14 chemoimmunotherapy of a secondary high-grade Non-Hodgkin's lymphoma. While lymphoma responded to the initial therapy with R-CHOP plus consolidation radiation therapy, the anemia was interpreted as pure red cell aplasia and responded to treatment with intravenous immunoglobulins. However, both diseases failed to respond to salvage therapies when they recurred simultaneously 4 months after the completion of primary therapy.

The occurrence of Parvovirus-B19 associated pure red cell aplasia during the chemoimmunotherapy of a NonHodgkin's lymphoma must be recognized and treated early in knowledge of the potentially adverse consequences associated with this rare viral reactivation syndrome. In the absence of feasible immunization strategies or antiviral drugs, it remains however unclear, whether this knowledge, and the implementation of currently available therapeutic resources will suffice to improve the treatment results of relapsed pure red cell aplasia in the setting of relapsed lymphoma. While remains unclear, whether the occurrence of Parvovirus-B19 associated pure red cell aplasia during the initial chemoimmunotherapy of B-cell NHL can be regarded as a sign of adverse prognosis and poor outcome, the combination of these two inter-related haematological disorders is undoubtedly associated with increased patient morbidity and, more likely than not, with decreased treatment efficacy.
\end{abstract}

Keywords: Parvovirus B19; Pure red cell aplasia; R-CHOP; Immunochemotherapy; Non-Hodgkin's lymphoma; Anemia; Prognosis

\section{Introduction}

Parvovirus B19 is a small non-enveloped single stranded DNA virus, which is characterized by its tropism for erythroid progenitor cells [1]. Rituximab is a chimeric monoclonal antibody against CD20 that depletes not only malignant B-cells but also normal B-cells thus impairing humoral and cellular immunity. Treatment with rituximab - with or without concomitant chemotherapy - can increase the risk of bacterial, viral and other infections; another important mechanism for the development of clinically significant infectious diseases after rituximab therapy is reactivation of viral infections such as cytomegalovirus (CMV), Epstein-Barr-virus (EBV) or Parvovirus B19.

Parvovirus B-19 reactivations with the subsequent development of pure red cell aplasia have been described in many different settings of compromised immunity:

$>$ as late complication of immunosuprression and graft-versushost disease after allogeneic bone marrow transplantation [2]

> as complication of different immunsuppressive regimens utilized after renal transplantation to prevent graft rejection $[3,4]$

as complication of immunsuppressive regimens utilized to prevent graft rejection after transplantation of other solid organs [5]

as specific complication of the immunological deficiencies observed in patients with human immunodeficiency virus (HIV) infections [6]
$>$ as an event occurring secondary to the antibody-mediated depletion of CD-20-positive lymphoid cells after primary rituximab therapy [7]

$>$ as an event occurring secondary to the immunusuppression associated with CHOP-chemotherapy in combination with antibody-mediated depletion of CD-20-positive lymphoid cells after rituximab (i.e. after R-CHOP) [8]

$>$ recently, as an event occurring in the context of rituximab maintenance therapy in follicular lymphoma [9]

The association of refractory lymphoma-relapse in combination to an equally refractory relapse of Parvo-Virus-associated B-19 reactivation has not been published, as to our knowledge.

\section{Case History}

We present the case of a 67-year-old man with a prior history of liposarcoma (in remission for ten years) who developed a secondary

${ }^{*}$ Corresponding author: PD Dr. med. Sebastian Fetscher, Sana Klinikum Lübeck $\mathrm{GmbH}$, Medizinische Klinik III, Hämatologie, internistische Onkologie, Immunologie und Tagesklinik, Kronsforder Allee 71-73, 23560 Lübeck, Germany, Tel: 0451585 1402; Fax: 0451585 1429; E-mail: s.fetscher@sana-luebeck.de

Received February 13, 2012; Accepted March 12, 2012; Published March 15 2012

Citation: Fetscher S, Merz H, Hartmann JT (2012) Parvovirus B19 Associated Pure Red Cell Aplasia Associated with R-CHOP Immunochemotherapy for Relapsed B-Cell Non-Hodgkin'S Lymphoma - An Indicator of A Poor Prognosis? J Cytol Histol 3:138. doi:10.4172/2157-7099.1000138

Copyright: (c) 2012 Fetscher S, et al. This is an open-access article distributed under the terms of the Creative Commons Attribution License, which permits unrestricted use, distribution, and reproduction in any medium, provided the original author and source are credited. 
Citation: Fetscher S, Merz H, Hartmann JT (2012) Parvovirus B19 Associated Pure Red Cell Aplasia Associated with R-CHOP Immunochemotherapy for Relapsed B-Cell Non-Hodgkin'S Lymphoma - An Indicator of A Poor Prognosis? J Cytol Histol 3:138. doi:10.4172/2157-7099.1000138

Page 2 of 4

high-grade, diffuse large B-cell Non-Hodgkins lymphoma (NHL) only one month after the diagnosis of a marginal-zone B-cell Non-Hodgkins lymphoma (MZL) was made.

The diagnosis of diffuse large B-cell NHL with bulky abdominal stage II was made in January 2008. The International Prognostic Index (IPI) was intermediate-high based on three risk-factors (age $>60$ years, ECOG 2, elevated Lactate Dehydrogenase (LDH)). Histology of a transcutaneous needle aspirate of the bulk tumor was consistent with a secondary high-grade lymphoma after a marginal zone NHL diagnosed during laparoscopy one month earlier.

From January to April 2008, the patient received five cycles of standard-dose R-CHOP-12 immunochemotherapy (consisting of Ritiuximab $375 \mathrm{mg} / \mathrm{m}^{2}$, Cyclophosphamide $750 \mathrm{mg} / \mathrm{m}^{2}$, Doxorubicin $50 \mathrm{mg} / \mathrm{m}^{2}$, Vincristin $1,4 \mathrm{mg} / \mathrm{m}^{2}$, all d1 i.v. and Prednisolone $50 \mathrm{mg} / \mathrm{m}^{2}$ d1q-5 p.o.) resulting in a very good partial remission of his NHL with a residual tumor in the area of the bulk that was marginally FDG-avid on PET-CT-examination in April 2008; radiation therapy of the residual bulk was the given at the dose of 46 Gray and completed in June 2008.

During this immunochemotherapy, the patient developed an increasingly severe and increasingly symptomatic anemia WHO I-II (with e.g. first-onset atrial fibrillation in early April 2008) as shown in table 1:

The anemia remained unexplained initially, puzzling the clinicians for the first four weeks; endoscopic examinations (gastrocopy, colonoscopy) showed no abnormalities, there were no signs of treatment- oder lymphoma-associated hemolysis (LDH was within normal range after 2 cycles of R-CHOP, Haptoglobin was persistently elevated, a Vitamin B12 or Folate deficiency could be ruled out). After transfusion of a total of 12 units of red packed red blood cells $(\mathrm{PRBC}+\mathrm{s})$ further examinations were performed. The clue to the diagnosis of Parvovirus B19 associated pure red cell aplasia was a reticulocyte count of zero in April 2008 - reticulocytopenic anemia being the hallmark finding in immune compromised patients with parvovirus B19 infection [1].

Bone marrow aspiration showed no evidence of infiltration by lymphoma cells, but a depletion of erythroid precursor cells, reduced granulopoesis, and proliferating megacaryopoesis (Figure 1). Positive polymerase chain reaction (PCR) for parvovirus B19 DNA in the patient's serum confirmed the diagnosis.

As treatment of this virus-induced haematological complication the patient received unspecific intravenous immunoglobulin IGIV from April through June 2008, which contained neutralizing antibodies to Parvovirus B19 [10] at a dosage of $0.1 \mathrm{~g} / \mathrm{kg}$. In accordance with published observations in a similar setting [11], a clinical response to IVIG was observed with reticulocytosis and increased haemoglobin concentrations; in contrast to the cited publications, however, a complete eradication of the viremia and persistent normalisation of the haemoglobin values was not achieved in our case.

In October 2008, the patient experienced lymphoma recurrence and a relapse of symptomatic anemia. This time, the patient responded only marginally and transiently to salvage chemotherapy of the lymphoma as well as to the re-introduction of the IVIG therapy. The treatment therefore changed to mere supportive measures in December 2008; the patient succumbed to refractory lymphoma progression associated with a refractory parvovirus B19-associated red cell aplasia in February of 2009.

\section{Discussion}

Many infectious complications have been associated with rituximab therapy or R-CHOP immunotherapy. The spectrum includes classic opportunistic infections such as pneumocystis jirovecii pneumonitis [12], severe viral infections such as fulminant hepatitis

\begin{tabular}{|c|c|c|c|}
\hline Datum & $\mathrm{Hb}$ g/dl & Transfusion requirement & Remarks \\
\hline 02.01 .08 & 12 & & \\
\hline 16.01 .08 & 11 & & \\
\hline 28.01 .08 & 10 & & \\
\hline 18.02.08 & 9 & & \\
\hline 03.03.08 & 8 & 2 units of packed-red-blood cells & \\
\hline 14.03.08 & 8 & 2 units of packed-red-blood cells & \\
\hline 25.03 .08 & 8 & 2 units of packed-red-blood cells & \\
\hline 08.04 .08 & 9 & 2 units of packed-red-blood cells & \\
\hline 13.04.08 & 8 & 2 units of packed-red-blood cells & \\
\hline 18.04.08 & 8 & 2 units of packed-red-blood cells & \\
\hline 20.04 .08 & 10 & & $\begin{array}{l}\text { Therapy: } 14 \text { doses of } 15 \\
\text { gm IVIV }\end{array}$ \\
\hline 19.06.08 & 14 & & $\begin{array}{l}\text { Beginning 23.04. end } \\
25.06 .08\end{array}$ \\
\hline 07.07.08 & 13 & & $\begin{array}{l}\text { PR of pure red cell } \\
\text { aplasia }\end{array}$ \\
\hline 12.08.08 & 13 & & PR of the NHL \\
\hline 15.10 .08 & 12 & & Lymphom relapse \\
\hline 20.10 .08 & 10 & & $\begin{array}{l}\text { Relapse pf pure red cell } \\
\text { aplasia }\end{array}$ \\
\hline 28.10 .08 & 8 & 2 units of packed-red-blood cells & $\begin{array}{l}\text { Therapy: } 12 \text { doses of } 15 \\
\text { gm IVIV }\end{array}$ \\
\hline 18.11.08 & 9 & 2 units of packed-red-blood cells & $\begin{array}{l}\text { Beginning 18.10. end } \\
30.11 .08\end{array}$ \\
\hline 23.11 .08 & 8 & 2 units of packed-red-blood cells & \\
\hline 28.11 .08 & 8 & 2 units of packed-red-blood cells & \\
\hline 30.11 .08 & 8 & 2 units of packed-red-blood cells & Refractory lymphoma \\
\hline 03.12 .08 & 7 & 2 units of packed-red-blood cells & $\begin{array}{l}\text { Refractory pure red cell } \\
\text { aplasia }\end{array}$ \\
\hline 20.12 .08 & 8 & 2 units of packed-red-blood cells & \\
\hline 30.12 .09 & 10 & & \\
\hline 15.01.09 & 8 & 2 units of packed-red-blood cells & \\
\hline 24.01 .09 & 8 & 2 units of packed-red-blood cells & \\
\hline 27.01 .09 & 8 & 2 units of packed-red-blood cells & \\
\hline 06.02 .09 & 9 & 2 units of packed-red-blood cells & \\
\hline
\end{tabular}

Table 1: Development of Hemoglobin values during Parvoviris-B19-Reactivation.

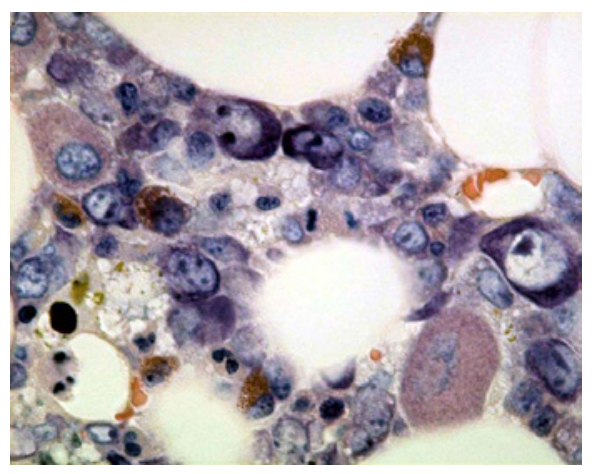

Giemsa-staining of our patient's bone marrow smear (original magnification 630x) showing dysplastic megacaryopoiesis, absence of erythroblasts

Figure 1: Bone marrow aspirate during the initial presentation of Parvovirus B19 associated pure red cell aplasia. 
after HBV reactivation [13] and aplastic crisis because of parvovirus B19 reactivation [7-9].

While the development of pneumocystis pneumonia can effectively be prevented by the prophylactic administration of Trimethoprim/ Sulfamethoxazole [12], reactivation of HBV can be prevented by prophylactic administration of lamivudine [13], and herpes infection can be prevented by prophylactic administration of acyclovir. On the other hand, a change of the immunosuppressive regimen in addition to administration of IVIG may helps to clear the infection in affected recipients of solid organ transplantation [5]. Even in patients with HIVinfection, successful strategies to deal with Parvovirus-B19-reactivation have been published [6]. However, there are currently no strategies available to prevent reactivation or infection with Parvovirus B19 in patients receiving Rituximab-based immunosuppressive combination therapies - and prediction of successful treatment with IVIG in these patients is notiously difficult and depends primarily on an adequate control of the underlying hematoloical malignancy [7-9].

Unfortunately, clinical trials with human recombinant parvovirus B19 vaccine had to be terminated due to vaccine-associated adverse events.

Treatment with IGIV is the standard treatment to control parvovirus B19 infection in immune compromised patients [1]. Not only the impairment of B-cell activity, but also T-cell depletion associated with the diagnosis of non-Hodgkin's lymphoma and its immunechemotherapy lead to parvovirus B19 reactivation. Although humoral immunity is thought to be the most important factor in coping with parvovirus B19 infection, several observations point to an important role of the cellular response system in clearing the infection $[2,4,14]$.

We describe the case of a patient with B-NHL who developed Parvovirus B19 associated pure red cell aplasia during R-CHOP-14 therapy. While the lymphoma and the pure red cell aplasia responded to the initial therapy (R-CHOP plus consolidation radiation therapy and treatment with IVIG, respectively), both diseases failed to respond to salvage therapies when the recurred simultaneously four months after the completion of primary therapy. The following conclusions and observations may be drawn from this case:

1. The case illustrates the difficulty to deal with a clinically significant viral reactivation in the absence of an efficient, specific antiviral medication. Clearly, the complex immunosupressed state of this patient caused by the lymphoma and its therapy are only partially corrected by the use of IVIG.

2. It remains unclear, whether the occurrence of Parvovirus-B19 associated pure red cell aplasia during the R-CHOPchemoimmunotherapy may be indicative of a more-thanaverage degree of immune incompetence associated with a particularly aggressive (and immunologically autoaggressive) lymphoma per se - or with a particular sensitivity of the individual patient to the immunosuppressive effects of R-CHOP-therapy. So far, no methods or guidelines have been published with regards to the prediction of this haematological complication or to the characterization of parameters that may help to identify patients at particular risk for the development of Parvovirus-B19 associated pure red cell aplasia.

3. It is clear, however, that the onset of Parvovirus-B19 associated pure red cell aplasia during the chemoimmunotherapy of a
Non-Hodgkin's lymphoma heralds a disadvantageous course of treatment with a potentially significant deterioration of prognosis.

Individual features or mediators of this adverse prognostic effect could include:

$>$ reduced efficacy of the chemotherapy by lack of oxygen carries (and thus lower-than-normal generation of oxygen radicals)

$>$ reduced efficacy of additional consolidation radiotherapy by lack of oxygen carries (and thus lower-than-normal generation of oxygen radicals)

$>$ reduction of chemotherapy dosage and increase of chemotherapy intervals due to secondary complications of anemia such as atrial fibrillation, depression and general physical deterioration and inactivity

$>$ reduced tolerance of crucial chemotherapy agents such as anthracyclins as a consequence of general deconditioning, reduced coronary oxygenation and cardiac arrhythmias

$>$ increased susceptibility to secondary infections by other microbial agents during the phase of Parvo-Virus-B-19 reactivation

$>$ negative effects of multiple blood transfusions (in this case 30 PRBC's in less than six months) with a significant iatrogenic iron load (possibly contributing to a pre-existing altered cardiac state)

$>$ negative effects of multiple transfusions of intravenous immunoglobulins such as allergic reactions and increased need for antiallergic pre-medication with further in desired side effects (steroids, antihistamines etc)

\section{Summary}

The occurrence of Parvovirus-B19 associated pure red cell aplasia during the chemoimmunotherapy of a Non-Hodgkin's lymphoma must be recognized and treated early in full knowledge of the potentially adverse complications and consequences associated with this rare, but clinically significant viral reactivation syndrome. In the absence of feasible immunization strategies or antiviral drugs, it remains unclear, whether the implementation of currently available therapeutic resources will improve the treatment results of relapsed pure red cell aplasia in the setting of relapsed lymphoma. While it remains unclear, whether the occurrence of Parvovirus-B19 associated pure red cell aplasia during the initial chemoimmunotherapy of B-cell NHL ca be regarded as a sign of adverse prognosis and poor outcome, the combination of these two inter-related haematological disorders is undoubtedly associated with increased patient morbidity and, more likely than not, decreased treatment efficacy.

\section{References}

1. Young NS, Brown KE (2004) Parvovirus B19. N Engl J Med 350: 586-597.

2. Hayes-Lattin B, Seipel TJ, Gatter K, Heinrich MC, Maziarz RT (2004) Pure red cell aplasia associated with parvovirus B19 infection occurring late after allogeneic bone marrow transplantation. Am J Hematol 75: 142-145.

3. Beckhoff A, Steffen I, Sandoz P, Hirsch HH, Schaub S (2007) Relapsing severe anaemia due to primary parvovirus B19 infection after renal transplantation: a case report and review of the literature. Nephrol Dial Transplant 22: 3660-3663.

4. Waldman M, Kopp JB (2007) Parvovirus B19 and the kidney. Clin J Am Soc Nephrol 2: S47-S56. 
Citation: Fetscher S, Merz H, Hartmann JT (2012) Parvovirus B19 Associated Pure Red Cell Aplasia Associated with R-CHOP Immunochemotherapy for Relapsed B-Cell Non-Hodgkin'S Lymphoma - An Indicator of A Poor Prognosis? J Cytol Histol 3:138. doi:10.4172/2157-7099.1000138

5. Geetha D, Zachary JB, Baldado HM, Kronz JD, Kraus ES (2000) Pure red cel aplasia caused by Parvovirus B19 infection in solid organ transplant recipients: a case report and review of literature. Clin Transplant 14: 586-591.

6. Frickhofen N, Abkowitz JL, Safford M, Berry JM, Antunez-de-Mayolo J, et al (1990) Persistent B19 parvovirus infection in patients infected with human immunodeficiency virus type 1 (HIV-1): a treatable cause of anemia in AIDS. Ann Intern Med 113: 926-933.

7. Sharma VR, Fleming DR, Slone SP (2000) Pure red cell aplasia due to parvovirus B19 in a patient treated with rituximab. Blood 96: 1184-1186.

8. Song KW, Mollee P, Patterson B, Brien W, Crump M (2002) Pure red cell aplasia due to parvovirus following treatment with $\mathrm{CHOP}$ and rituximab for B-cell lymphoma. Br J Haematol 119: 125-127.

9. Liapis K, Harhalakis N, Stefanou G, Apostolidis J (2012) Severe anemia during rituximab maintenance therapy for follicular lymphoma. J Clin Oncol 30: e95-e96.
10. Sawada K, Fujishima N, Hirokawa M (2008) Acquired pure red cell aplasia: updated review of treatment. $\mathrm{Br} \mathrm{J}$ Haematol 142: 505-514.

11. Isobe $Y$, Sugimoto K, Shiraki Y, Nishitani M, Koike K, et al. (2004) Successfu high-titer immunoglobulin therapy for persistent parvovirus B19 infection in a lymphoma patient treated with rituximab-combined chemotherapy. Am J Hematol 77: 370-373.

12. Hardak E, Oren I, Dann EJ, Yigla M, Faibish T, et al. (2012) The Increased Risk for Pneumocystis Pneumonia in Patients Receiving Rituximab-CHOP-14 Can Be Prevented by the Administration of Trimethoprim/Sulfamethoxazole: A Single-Center Experience. Acta Haematol 127: 110-114.

13. Hamaki T, Kami M, Kusumi E, Ueyama J, Miyakoshi S, et al. (2001) Prophylaxis of hepatitis $B$ reactivation using lamivudine in a patient receiving rituximab. Am J Hematol 68: 292-294.

14. Cassinotti P, Burtonboy G, Fopp M, Siegl G (1997) Evidence for persistence of human parvovirus B19 DNA in bone marrow. J Med Virol 53: 229-232. 